๑) Open Access Full Text Article

\title{
Assessing suicide management skills of emergency medical services providers before and after suicide intervention/prevention training with Lithuanian version of suicide intervention response inventory
}

This article was published in the following Dove Press journal:

Neuropsychiatric Disease and Treatment

\section{Aidana Lygnugaryte- Griksiene \\ Darius Leskauskas}

Department of Psychiatry at Lithuanian University of Health Sciences, Kaunas, Lithuania
Correspondence: Aidana LygnugaryteGriksiene

Psychiatry Clinic at Lithuanian University of Health Sciences, Mickeviciaus Str. 9, Kaunas, LT-44307, Lithuania

Tel +37060395524

Email aidana.lygnugaryte@gmail.com
Background: Effective suicide management skills of emergency medical services (EMS) providers are crucially important in Lithuania, which has the highest suicide rates in Europe. Methods: Respondents were 268 EMS providers, doctors $(n=78)$ and nurses $(n=190)$, who agreed to participate in suicide prevention/intervention training and completed the survey twice. Study was conducted in five steps: adaptation of Lithuanian version of Suicide Intervention Response Inventory (SIRI-LT); initial assessment of suicide counseling skills of the EMS providers using SIRI-LT; suicide prevention/intervention training; second assessment of suicide counseling skills using SIRI-LT 6 months after training; data analysis evaluating the skills and effectiveness of the training among different groups of EMS providers (doctors vs nurses, age groups).

Results: SIRI-LT showed good internal consistency: Cronbach's alpha score of 0.85 (pretest) and 0.73 (posttest). The value of Kaiser-Meyer-Olkin measure of sampling adequacy was 0.849. A four-factor solution was forced and accounted for $40.8 \%$ of the variance. The SIRI-LT mean total scores before suicide prevention/intervention training were significantly higher for doctors than for nurses (13.01 \pm 5.24 vs $11.36 \pm 5$.14, respectively; $P=0.031)$. Younger respondents with a shorter period of employment and heavier workload were significantly more effective at suicide management than older respondents with a longer period of employment and lower workload. After suicide prevention/intervention training, SIRI-LT mean total scores decreased for doctors (13.0 \pm 5.24 vs $11.02 \pm 4.76 ; P=0.031)$ and significantly increased in older ( $\geq 55$ age) respondents ( $11.85 \pm 3.82$ vs $9.28 \pm 4.44 ; P=0.022$ ).

Conclusion: SIRI-LT has good internal consistency and can be considered a good instrument for assessing suicide management skills of EMS providers. Our results suggest that ability to find appropriate responses to suicide situations may be multidimensional, related to cultural setting and influenced by age, education, motivation, engagement, and emotional distraction. Particular attention should be paid to active listening and empathic communication skills when developing suicide prevention/intervention training for EMS providers.

Keywords: emergency medical service, suicide intervention response inventory, suicide, training

\section{Introduction}

World Health Organization data show that Lithuania has the highest suicide rate in Europe and the fifth highest in the world. ${ }^{1}$ During the past decade, suicide rates in 
Lithuania had exceeded 30 suicide deaths per 100,000 inhabitants; it is three times higher than the average in European Union (EU). ${ }^{2-4}$

Emergency medical service (EMS) providers, especially doctors, nurses, and psychologists in primary care and emergency departments have considerable exposure to persons with suicidal behavior..$^{5-7}$ These health care professionals are close to potentially vulnerable persons and can identify people with the risk of suicide, provide initial support and referral for further assistance. Therefore, the communication and actions of the EMS providers determine what kinds of help patients receive. ${ }^{8}$ While such contacts provide the opportunity to identify and manage those at risk of suicide, these contacts are often rated as challenging and distressing, which indicates the need for well-skilled professionals. ${ }^{9}$

Systematic reviews and meta-analysis have shown that suicide prevention programs are effective for protective and emergency services employees (13 studies were analyzed). Most studies evaluated the suicide prevention programs for military personnel or fire-fighters. There were no eligible effectiveness studies of suicide prevention programs for EMS providers. ${ }^{10,11}$

Despite the high suicide rates in Lithuania, until now, there are no structured suicide intervention/prevention skills training programs for health care professionals. Moreover, no tools were developed for the evaluation of the efficacy of such trainings in Lithuanian language.

Suicide Intervention Response Inventory (SIRI), developed by Neimeyer and MacInnes in 1981, is one of the most validated and reliable self-administered measure for assessing suicide counseling skills of professionals and para-professionals working with potentially suicidal individuals. ${ }^{12,13}$ The aim of this study was to adapt the Lithuanian version of SIRI (SIRI-LT) and to assess suicide management skills in EMS providers before and after the suicide intervention/ prevention training.

\section{Methods}

\section{Study design}

The study was conducted from March 2015 till August 2016 in five steps:

Step I: Adaptation of SIRI-LT

Step II: First assessment of suicide management skills of the EMS providers using SIRI-LT prior to suicide prevention/intervention training

Step III: Suicide prevention/intervention training

Step IV: Second assessment of suicide management skills of EMS providers using SIRI-LT 6 months after suicide prevention/intervention training
Step V: Data analysis evaluating the skills and effectiveness of the training among different groups of EMS providers (doctors vs nurses, age groups).

\section{Ethical approval}

The approval to conduct the study was issued by the Kaunas Regional Committee on Biomedical Research Ethics under the Lithuanian Bioethics Committee, Approval No BE-2-15. All study participants signed personal informed consent forms before the study procedures. Consent forms for participation in the study were obtained from the administrations of involved health care institutions.

\section{Respondents and settings}

The study was conducted in Utena County, which was selected as the region with the highest suicide rates in Lithuania. EMS providers of four regional hospitals were involved in this study. Three hundred seventy-six doctors and nurses working in the EMS agreed to participate in the suicide prevention/intervention training. Two hundred sixty-eight participants had answered the questionnaires in the first study assessment (response rate $-71 \%$ ). Second assessment was completed by 226 respondents (response rate $-84 \%$ of the analyzed sample). The analyzed sample consisted of 78 doctors and 190 nurses with age ranging from 22 to 84 (mean age 47.28 99.52 years). Sociodemographic characteristics of the study sample are presented in Table 1.

Table I Sociodemographic characteristics of study participants, $\mathrm{n}=268$

\begin{tabular}{|l|l|l|l|}
\hline Characteristics & $\mathbf{n}$ & $\%$ & $P$-value \\
\hline Gender & & & $\chi^{2}=241.54 ; P=0.00$ \\
\hline$\quad$ Male & 7 & 2.6 & \\
$\quad$ Female & 261 & 97.4 & \\
\hline $\begin{array}{l}\text { Age (years), range } \\
\text { Mean (SD) }\end{array}$ & $22-84$ & & $\chi^{2}=130.16 ; P=0.00$ \\
\hline $\begin{array}{l}\text { Age groups (years) } \\
\quad 445\end{array}$ & $47.28(9.52)$ & & \\
$\quad 45-54$ & 113 & 42 & \\
$\quad \geq 55$ & 102 & 38 & \\
\hline $\begin{array}{l}\text { Employment period (years) } \\
\text { Mean (SD) }\end{array}$ & $24.89(10.22)$ & & \\
\hline Employment groups (years) & & 20 & \\
$\quad<15$ & 42 & 15.7 & \\
$\quad$ I5-29 & 125 & 46.6 & \\
$\quad \geq 30$ & 101 & 37.7 & \\
\hline Professional position & & & $\chi^{2}=46.80 ; P=0.00$ \\
\hline$\quad$ Doctor & 78 & 29 & \\
$\quad$ Nurse & 190 & 71 & \\
\hline
\end{tabular}




\section{Survey instrument: SIRI}

SIRI aims to assess the quality of suicide intervention skills and consists of 25 items, each with two possible responses for helpers dealing with a suicidal individual. One response is considered facilitative to effective intervention, whereas the other one is neutral or deleterious, according to crisis intervention theory.

Respondents had to rate the appropriateness of each response alternative on a seven-point Likert scale from -3 (very inappropriate) to 3 (very appropriate). SIRI scores were calculated based on the original version of SIRI: correct response was rated as 1 , while incorrect response was rated 0 . The total sum of all ratings were calculated and evaluated. Total SIRI scores could range from 0 to 25 (the maximum tally of correct responses). No point was awarded for blanks or if the same was given to each option within an item, because this reflects inability to discriminate a preferred from a nonpreferred response.

SIRI-LT was adapted after the double translation and language adaptation in a pilot study with 25 individuals.

\section{Suicide prevention/intervention training in Lithuania}

In 2015-2016, Lithuanian University of Health Sciences in cooperation with Vilnius Republican Psychiatric Hospital and Crisis Research Center had implemented suicide intervention/prevention training "Psychological Assistance Skills in Emergency Medical Aid" as a part of a project "Crisis Intervention: Training of Emergency Medicine Providers" funded by the grant of EU (this study was independent and not supported by the grant). The duration of the training was 32 hours (4 days). Training was implemented by psychiatrists and psychologists trained by Professor Jeffrey T. Mitchell from the University of Maryland and the International Critical Incident Stress Foundation. ${ }^{14}$ Training included theory seminars, role-playing workshops, and group discussions. It encompassed issues such as attitudes toward suicide, causes of suicidal behavior, psychological state of a suicidal individual, suicide risk assessment, recognizable and subtle signs of suicidal behavior, close contact with high-risk individuals, follow-up measures, and the training of skills for coping with stress.

\section{Statistical analyses}

Distributions of sociodemographic characteristics of study participants were presented as means with SD for continuous variables and as numbers (percentages) for categorical variables. Total score variables of the SIRI-LT, checked by Shapiro-Wilk test showed normal distribution of the variables. Evaluation of internal consistency of the scale was based on Cronbach's alpha model statistics. Mann-Whitney $U$ criterion was used to test median differences between two groups. Wilcoxon criterion was used to verify the statistical significance of the changes of the average scores for individual SIRI-LT questions. Difference of distribution of SIRI-LT scores depending on age and position was calculated using chi square $\left(\chi^{2}\right)$ criterion. Factor analysis was performed using varimax rotation. Statistical data were analyzed using SPSS 21.0 (Statistical Package for Social Science 21.0 for Windows) software. The significance level of statistical hypotheses was chosen as $P<0.05$.

\section{Results}

Internal consistency of the SIRI-LT was good with Cronbach's alpha score of 0.85 before training and 0.73 after training (see Table 2). To identify inductively the component skills assessed by the SIRI-LT, we choose SPSS analysis with varimax rotation for identifying "simple structure". The value of Kaiser-Meyer-Olkin measure of sampling adequacy was 0.849. A four-factor solution was forced and accounted for $40.8 \%$ of the variance. Factor I was largest and consisted of eleven items. Seven items met the $\geq 0.5$ criteria, other items met the 0.3 criteria. Analysis of the content of the items on this factor in the simple-structure solution reveals two common patterns. First pattern: correct responses by caregiver when attending to the problem presented by the client and reflecting its' essential character, often by attending to the feelings implicit in communication. For example, a clients' self-critical appraisal of her "terrible" thoughts and her concern that she could never share them with anyone. The preferred caregiver reply reframes these thoughts as "frightening" and hypothesizes that the client imagines others would be "shocked" to hear them. Second pattern: active intervention consisted of directive, crisis-intervention remarks such as "I want you to put down the gun so we can talk." Because facilitative replies in this category tend to restate the client's concern, carry it one step further, and include directive caregivers' actions, factor I was identified as "Elaboration of the Complaint and Active Response".

Factor II consisted of nine items. The common denominator among these items was the tendency to include a restatement or labeling of the clients' negative affect in correct replies (anger, hurt, depression, or loneliness), whereas nonpreferred answers represented intellectualized, defensive, or matter-of-fact responses on the part of the helper. Thus, these questions seemed to measure the respondents' engagement in "facilitative responding" or provision of "accurate empathy". ${ }^{15}$ For this reason, factor II was identified 
Table 2 SIRI scores and factor pattern loadings (Varimax rotation)

\begin{tabular}{|c|c|c|c|c|}
\hline \multirow[t]{2}{*}{ SIRI items } & \multicolumn{4}{|l|}{ Factors } \\
\hline & $\begin{array}{l}\text { Factor I: } \\
\text { Elaboration of the complaint } \\
\text { and active response }\end{array}$ & $\begin{array}{l}\text { Factor II: } \\
\text { Reflection of } \\
\text { negative feelings }\end{array}$ & Factor III & Factor IV \\
\hline 23 & 0.699 & & & \\
\hline 15 & 0.629 & & & \\
\hline 19 & 0.606 & & & \\
\hline 25 & 0.594 & & & \\
\hline 17 & 0.577 & & & \\
\hline 18 & 0.565 & & & \\
\hline 2 & 0.520 & & & \\
\hline 14 & 0.475 & & & \\
\hline 8 & 0.440 & & & \\
\hline 20 & 0.372 & & & 0.355 \\
\hline I & 0.322 & & & \\
\hline 16 & & 0.640 & & \\
\hline 13 & & 0.608 & & \\
\hline 6 & & 0.590 & & \\
\hline 4 & & 0.569 & & \\
\hline 9 & & 0.545 & & 0.352 \\
\hline 22 & & 0.478 & & \\
\hline 24 & & 0.470 & & \\
\hline 3 & & 0.407 & & \\
\hline 12 & & 0.260 & & \\
\hline 5 & & & 0.640 & \\
\hline 21 & & & 0.596 & \\
\hline 7 & & & 0.553 & \\
\hline 11 & & & 0.163 & -0.634 \\
\hline 10 & & & 0.295 & 0.508 \\
\hline $\begin{array}{l}\text { Cronbach's alpha } \\
\text { (total } 40.8 \% \text { of variance) }\end{array}$ & 0.764 & 0.735 & 0.443 & 0.329 \\
\hline
\end{tabular}

Abbreviation: SIRI, Suicide Intervention Response Inventory.

as "Reflection of Negative Feelings". Factor III consisted of five items, but only three items had loadings $>0.5$, Cronbach's alpha -0.443 . Factor IV consisted of four items, but none of these were pure, Cronbach's alpha - 0.329. Therefore, we left the third and fourth factors uninterpretable. Mean total scores of SIRI-LT before suicide prevention/ intervention training were significantly higher for doctors than for nurses $(13.01 \pm 5.24$ vs $11.36 \pm 5.14 ; P=0.031$; Table 3). Results in Table 4 show that younger respondents with a shorter period of employment and heavier workload were significantly more effective in suicide management than older respondents with a longer period of employment and lower workload. This difference was more significant in the group of doctors.

After suicide prevention/intervention training, SIRI-LT mean total scores decreased for doctors (13.0 \pm 5.24 vs
11.02 $\pm 4.76 ; P=0.031)$ and did not change for nurses (11.36 \pm 5.14 vs $11.38 \pm 4.40 ; P=0.933$; Table 3$)$. Total SIRI-LT scores did not change significantly after the training in younger respondents but significantly increased in $>55$ years respondents $(9.28 \pm 4.44$ vs $11.85 \pm 3.82 ; P=0.022)$.

Table 3 The SIRI-LT total scores before and after suicide prevention/intervention training among doctors and nurses

\begin{tabular}{|l|l|l|l|l|l|}
\hline \multirow{2}{*}{} & \multicolumn{2}{|l|}{ Before training } & \multicolumn{2}{l|}{ After training } & P-value \\
\cline { 2 - 5 } & Mean & SD & Mean & SD & Pre vs post \\
\hline Doctors & $13.0 \mathrm{I}$ & 5.24 & $\mathrm{II} .02$ & 4.76 & $0.03 \mathrm{I}^{*}$ \\
\hline Nurses & $\mathrm{II} .36$ & 5.14 & $\mathrm{II} .38$ & 4.40 & 0.933 \\
\hline Total & $\mathrm{II} .85$ & $5.2 \mathrm{I}$ & $\mathrm{I} 1.24$ & 4.48 & 0.250 \\
\hline
\end{tabular}

Note: Significant difference: $*<0.05$.

Abbreviation: SIRI-LT, Lithuanian version of Suicide Intervention Response Inventory. 
Table 4 Comparison between suicide intervention skills (SIRI-LT) and sociodemographic characteristics

\begin{tabular}{|c|c|c|c|c|c|c|}
\hline $\begin{array}{l}\text { Sociodemographic } \\
\text { characteristics }\end{array}$ & $n$ & SIRI mean \pm SD & Mean rank & Mann-Whitney U & $\bar{Z}$ & $P$-value \\
\hline \multicolumn{4}{|l|}{ Age (years) } & \multirow[t]{3}{*}{$4,721.00$} & \multirow[t]{3}{*}{-6.43} & \multirow[t]{3}{*}{$<0.00 I^{*}$} \\
\hline$\leq 47$ & 137 & $|3.90 \pm 4.4|$ & 161.54 & & & \\
\hline$\geq 48$ & 127 & $9.63 \pm 5.18$ & 101.17 & & & \\
\hline \multicolumn{4}{|l|}{ Employment period } & \multirow[t]{3}{*}{$4,132.50$} & \multirow[t]{3}{*}{-6.09} & \multirow[t]{3}{*}{$<0.00 I^{*}$} \\
\hline Up to 25 years & 123 & $14.07 \pm 4.55$ & 150.40 & & & \\
\hline From 26 years & 120 & $9.86 \pm 4.94$ & 95.37 & & & \\
\hline \multicolumn{4}{|l|}{ Workload } & \multirow[t]{3}{*}{$5,889.00$} & \multirow[t]{3}{*}{-3.13} & \multirow[t]{3}{*}{$<0.01 * *$} \\
\hline$\leq 30$ hours per week & 184 & $11.19 \pm 5.21$ & $|24.5|$ & & & \\
\hline$\geq 40$ hours per week & 84 & $13.32 \pm 4.93$ & 156.39 & & & \\
\hline
\end{tabular}

Note: Significant difference: $*<0.001 ; * *<0.01$.

Abbreviation: SIRI-LT, Lithuanian version of Suicide Intervention Response Inventory.

Changes of the specific SIRI-LT items scores are presented in Table 5 (for doctors) and Table 6 (for nurses). Changes in the doctors' scores occurred due to significant decrease of the scores for the items 3 ("But my thoughts have been so terrible ... I could never tell them to anybody"), 4 ("No one can understand the kind of pain I've been through. Sometimes I just feel like I have to hurt myself, so I cut my wrists"), 5 ("What are you anyway? Are you a doctor? How do you know what I've been going through? You've probably had it pretty soft"), 10 ("How would you be able to help me? Have you ever wanted to commit suicide?"), 15 ("Is it true that many people feel the same way? I thought that I was the only one who had such terrifying, sinful thoughts"), 22 ("I tried going to a therapist once before, but it didn't help ... Nothing I do now will change anything"), and 23 ("My psychiatrist tells me that I'm experiencing anxiety neurosis. Do you think that that is exactly what's wrong with me?"; Table 5). Increase for the nurses was observed in items 13 ("I don't know why I'm calling you. My family is financially well off, and my husband spends plenty of time with me, even though he has a successful law career. Even my kids have been doing well. They get good marks at school and have lots of free time activities with their friends. But nothing seems to interest me. Life is just a bore ...") and 16 ("I'm so lonely, so tired. [crying] There just isn't anywhere left to turn"; Table 6). Based on our factor analysis, most of these questions $(3,4,5,13,16,22)$ are attributable to factor II - Reflection of Negative Feelings.

\section{Discussion}

This study was based on the first project in Lithuania to develop a suicide prevention/intervention training program

Table 5 The significant changes of Suicide Intervention Response Inventory (SIRI-LT) item scores before and after suicide prevention/ intervention training among doctors $(n=78)$

\begin{tabular}{|c|c|c|c|c|c|}
\hline \multirow[t]{2}{*}{ Item numbers } & \multicolumn{2}{|c|}{ Before training } & \multicolumn{2}{|c|}{ After training } & \multirow{2}{*}{$\begin{array}{l}\text { P-value } \\
\text { Pre vs post }\end{array}$} \\
\hline & Mean & SD & Mean & SD & \\
\hline 3. But my thoughts were so terrible ... I could never tell anyone about them. & 0.37 & 0.49 & $0.20 * *$ & 0.40 & 0.009 \\
\hline $\begin{array}{l}\text { 4. Nobody can understand the pain which l've experienced. Sometimes I just feel that } \\
\text { I need to mutilate myself, and that's why I cut my wrists. }\end{array}$ & 0.62 & 0.49 & $0.31 * * *$ & 0.47 & $<0.000$ \\
\hline $\begin{array}{l}\text { 5. In any case, who are you? Are you a doctor? How can you possibly know what I have } \\
\text { been through? You've probably had it much easier. }\end{array}$ & 0.58 & 0.50 & $0.41 * *$ & 0.50 & 0.047 \\
\hline 10. How would you be able to help me? Have you ever wanted to commit suicide? & 0.64 & 0.48 & $0.45 * *$ & 0.50 & 0.039 \\
\hline $\begin{array}{l}\text { 15. Is it true that many people feel the same way? I thought that I was the only one who } \\
\text { had such terrifying, sinful thoughts. }\end{array}$ & 0.86 & 0.35 & $0.66 * *$ & 0.48 & 0.027 \\
\hline $\begin{array}{l}\text { 22. Once, some time ago, I tried going to a therapist, but it didn't help ... Whatever I do } \\
\text { now, nothing is going to change. }\end{array}$ & 0.59 & 0.49 & $0.42 * *$ & 0.50 & 0.021 \\
\hline $\begin{array}{l}\text { 23. My psychiatrist tells me that l'm experiencing anxiety neurosis. Do you think that that is } \\
\text { exactly what's wrong with me? }\end{array}$ & 0.88 & 0.33 & $0.69 * *$ & 0.47 & 0.015 \\
\hline Total score & 13.01 & 5.24 & $11.02 * *$ & 4.76 & 0.031 \\
\hline
\end{tabular}

Note: Significant difference: $* *<0.01$; $* * *<0.001$.

Abbreviation: SIRI-LT, Lithuanian version of Suicide Intervention Response Inventory. 
Table 6 The significant changes of SIRI-LT item scores before and after suicide prevention/intervention training among nurses $(n=190)$

\begin{tabular}{|c|c|c|c|c|c|}
\hline \multirow[t]{2}{*}{ Item numbers } & \multicolumn{2}{|c|}{$\begin{array}{l}\text { Before } \\
\text { training }\end{array}$} & \multicolumn{2}{|c|}{$\begin{array}{l}\text { After } \\
\text { training }\end{array}$} & \multirow[t]{2}{*}{$\begin{array}{l}P \text {-value } \\
\text { Pre vs post }\end{array}$} \\
\hline & Mean & SD & Mean & SD & \\
\hline 3. But my thoughts were so terrible ... I could never tell anyone about them. & 0.34 & 0.47 & $0.21 *$ & 0.41 & 0.010 \\
\hline $\begin{array}{l}\text { 13. I don't know why l'm calling you. My family is affluent, and my husband spends enough } \\
\text { time with me despite his successful career in law. Even my children are doing well. They } \\
\text { get good grades at school and they have plenty of leisure activities with their friends. But it } \\
\text { seems that nothing interests me anymore. Life is just a drag. }\end{array}$ & 0.09 & 0.29 & $0.18^{*}$ & 0.39 & 0.019 \\
\hline 16. I am so lonely, so tired. [sobbing] There's just nothing left to turn to. & 0.33 & 0.47 & $0.44 *$ & 0.50 & 0.030 \\
\hline 19. Regardless, why should you care about me? & 0.70 & 0.46 & $0.59 *$ & 0.49 & 0.022 \\
\hline $\begin{array}{l}\text { 23. My psychiatrist tells me that l'm experiencing anxiety neurosis. Do you think that that is } \\
\text { exactly what's wrong with me? }\end{array}$ & 0.86 & 0.35 & $0.74 *$ & 0.44 & 0.023 \\
\hline Total score & 11.36 & 5.14 & 11.38 & 4.40 & 0.933 \\
\hline
\end{tabular}

Note: Significant difference: $*<0.01$.

Abbreviation: SIRI-LT, Lithuanian version of Suicide Intervention Response Inventory.

for EMS providers and to evaluate their suicide management skills with a standardized methodology, SIRI-LT. We found that SIRI-LT had good internal consistency. The internal consistency of SIRI-LT in this study was similar to the one reported by the authors of the inventory ${ }^{16}$ and higher than that reported in Japanese validation of the inventory. ${ }^{17}$

Repetitive evaluation with SIRI-LT had showed that implemented suicide intervention/prevention training program had an impact on certain suicide management skills but had not significantly improved total skills of EMS providers. We found that after suicide prevention/intervention training, total scores of SIRI-LT had not changed for nurses but decreased for doctors. We think that this change could occur due to factors such as motivation, engagement, and emotional distraction. Providers of the training reported that nurses were more acceptant to the training, more involved in discussions, asked more questions, participated consistently, and emphasized the lack of knowledge in the field. Whereas, doctors were more often distracted by phone calls during the training, were leaving the auditorium to talk, emphasized that they had enough knowledge in the field, questioned the effectiveness of the training, were defensive, shared less, were less involved in discussions, avoided participation in role-play exercises or sharing personal experience, and did not express their emotions. Studies conducted in Lithuania show that a high incidence of suicides is determined, among other factors, by a more positive attitude toward suicide as an acceptable solution to problems than in other countries. However, other pieces of research show that special training may change negative attitudes. The attitudes of those who undergo training are more favorable toward suicide prevention. ${ }^{18}$ Studies examining the impact of attitudes on suicide intervention skills suggest that negative attitudes toward suicide are associated with inferior suicide intervention skills. ${ }^{19,20}$

Analysis of the answers to individual questions of SIRI-LT revealed that the scores of the questions 3, 4, 5, 10, 15,22 , and 23 decreased significantly for doctors, while the scores of questions 13 and 16 increased for nurses. Based on our factor analysis, these questions are attributable to factor II - Reflection of Negative Feelings. It allows us to hypothesize that these skills are mostly influenced by the training program. Kato et $\mathrm{al}^{13}$ in a similar study had found that SIRI total score increased immediately after the intervention but this improvement did not persist for 6 months. Some authors consider that evaluating a better response to certain items of the inventory can be complicated. This difficulty might occur due to differences in suicide methods and suicide intervention approaches between the countries. The idea of the suicidal process as a continuous and smooth evolution from thoughts to plans and attempts of suicide needs to be further investigated as it seems to be dependent on the cultural setting. Therefore, evaluation methods including sociocultural factors should be developed for a more precise skills assessment for specialists working with suicidal persons. ${ }^{21,22}$

In our study, we found that age had an influence on SIRI-LT total scores and their changes after the training. Younger EMS providers had higher SIRI-LT total scores before the training and their scores had not changed significantly after the training. SIRI-LT scores had significantly increased after the training for the respondents $>55$ years old. This finding is inconsistent with reports from the previous studies where no significant relationships between SIRI 
scores and demographic variables were found..$^{12,17,20,23}$ Again, this points to the possible influence of cultural setting. We hypothesize that higher SIRI-LT score in younger EMS providers can be explained by the changes in medical education/training and attitudes toward suicide prevention, which occurred after Lithuania gained independence and suicide prevention was started. It could also explain why training program had the biggest impact on participants $>55$ years of age.

Our study was informative concerning both the components of suicide counseling skills and the factorial structure of the SIRI-LT. Our factor analysis had discovered two SIRI-LT factors that match with the basic dimensions of the skills: 1) Elaboration of the Complaint and Active response, and 2) Reflection of Negative Feelings. It is consistent with previous studies that had established two SIRI factors: Reflection of feelings and Active intervention. ${ }^{24}$ But our results differ from another study that had established four SIRI factors: Elaboration of the Complaint, Exploration of Suicidality, Involvement, and Reflection of Negative Feelings. In our factor analysis, most items had high loadings ( 0.5 or 0.6 ), while in previous studies on SIRI factor analysis most items had loadings 0.3 or lower. Considering that previous studies had established SIRI as a valid and reliable index of suicide counseling skill, we can suggest that ability to discover appropriate responses to crisis situations may indeed be multidimensional. ${ }^{25}$

Adaptation of such a model could have both practical and psychometric implications. For example, components of suicide intervention skills suggested here, if corroborated, could provide an empirical basis for improving training programs in crisis counseling. Typically, the emphasis in paraprofessional training programs is on active listening or empathic communication skills. ${ }^{26}$ However, specific training in the directive management of suicidal crises is lacking in many medical and paraprofessional contexts. ${ }^{16,27}$ Analysis of the scores for different factors of SIRI offers better possibilities to assess if training programs are appropriately addressing all four domains of the skills (active listening, focusing complaints, showing involvement, and exploring suicidality). ${ }^{25}$ Considering results of our study, we would suggest paying more attention to the skills of active listening or empathic communication skills when developing suicide prevention/interventions training for EMS providers in Lithuania.

Considering the strengths and limitations of our study, we want to mention that it is the first Lithuanian report about development of suicide prevention/intervention training program for EMS providers and its evaluation with the standardized method for suicide management skills SIRI-LT. Most studies on suicide prevention/intervention had been carried out from the perspective of the patients, whereas we have attempted to understand the mindset of EMS providers better. Two parties are involved in the process of assisting a suicidal patient, and it is essential to assess both of them to understand how they mutually influence and affect each other. The assessment was performed twice - before the training and 6 months afterward. As the limitations to this study, we consider its confinement with only one county and relatively small sample size without control group.

\section{Conclusion}

SIRI-LT has good internal consistency and can be considered a good instrument for assessing suicide management skills of EMS providers. Two SIRI-LT factors had been established: Elaboration of the Complaint and Active Response, and Reflection of Negative Feelings. Our results suggest that the ability to find appropriate responses to suicide situations may be multidimensional, related to cultural setting and influenced by age, education, motivation, engagement, and emotional distraction. Particular attention should be paid to the active listening and empathic communication skills when developing suicide prevention/intervention training for EMS providers in Lithuania.

Based on the results of our study, we would recommend to enhance motivation and engagement and to reduce emotional distractions of doctors when organizing trainings for suicide management. To increase internal motivation of training participants by taking into account their personal attitudes, expectations about the topics, providing space for sharing their personal and professional experience.

\section{Acknowledgments}

We wish to thank the study participants for their valuable contribution. The authors also want to thank Lithuanian University of Health Sciences, Vilnius Republican Psychiatric Hospital, and Crisis Research Centre for the opportunity to conduct a study.

\section{Disclosure}

The authors report no conflicts of interest in this work.

\section{References}

1. Who.int [homepage on the Internet]. World Health Organization: suicide rates, age standardized - data by country [updated April 4, 2017; cited Jan 16, 2018]. Available from: http://www.who.int/. Accessed May 30, 2018. 
2. Stat.gov.lt [homepage on the Internet]. Lithuania statistics: suicide statistics in Lithuania [updated May 18, 2018; cited May 21, 2018]. Available from: http://www.stat.gov.lt/. Accessed May 30, 2018.

3. Hi.lt [homepage on the Internet]. Lithuania: Institute of Hygiene, suicide statistics online [updated May 30, 2018; cited May 30, 2018]. Available from: http://www.hi.lt/. Accessed May 30, 2018.

4. Vpsc.lrv.lt [homepage on the Internet]. Lithuania: State Center for Mental Health [updated Jan 29, 2018; cited Feb 2, 2018]. Available from: http://vpsc.1rv.lt/. Accessed May 30, 2018.

5. Houston K, Haw C, Townsend E, Hawton K. General practitioner contacts with patients before and after deliberate self harm. Br J Gen Pract. 2003;53(490):365-370.

6. Andersen UA, Andersen M, Rosholm JU, Gram LF. Contacts to the health care system prior to suicide: a comprehensive analysis using registers for general and psychiatric hospital admissions, contacts to general practitioners and practising specialists and drug prescriptions. Acta Psychiatr Scand. 2000;102(2):126-134.

7. Luoma JB, Martin CE, Pearson JL. Contact with mental health and primary care providers before suicide: a review of the evidence. $A m J$ Psychiatry. 2002;159(6):909-916.

8. Kaniwa I, Kawanishi C, Suda A, Hirayasu Y. Effects of educating local government officers and healthcare and welfare professionals in suicide prevention. Int J Environ Res Public Health. 2012;9(3): $712-721$.

9. Botega NJ, Reginato DG, da Silva SV, et al. Nursing personnel attitudes towards suicide: the development of a measure scale. Braz J Psychiatr. 2005;27(4):315-318.

10. Witt K, Milner A, Allisey A, Davenport L, LaMontagne AD. Effectiveness of suicide prevention programs for emergency and protective services employees: a systematic review and meta-analysis. Am J Ind Med. 2017;60(4):394-407.

11. Schwartz-Lifshitz M, Zalsman G, Giner L, Oquendo MA. Can we really prevent suicide? Curr Psychiatry Rep. 2012;14(6):624-633.

12. Neimeyer RA, Bonnelle K. The Suicide Intervention Response Inventory: a revision and validation. Death Stud. 1997;21(1):59-81.

13. Kato TA, Suzuki Y, Sato R, et al. Development of 2-hour suicide intervention program among medical residents: first pilot trial. Psychiatry Clin Neurosci. 2010;64(5):531-540.
14. Mitchell JT. Crisis Intervention and Critical Incident Stress Management: A Defense of the Field. Ellicott City, MD: International Critical Incident Stress Foundation, Inc.; 2004. Available from: http://www. icisf.org/wp-content/uploads/2013/04/Crisis-Intervention-and-CriticalIncident-Stress-Management-a-defense-of-the-field.pdf. Accessed November 23, 2018.

15. Carkhuff R. The Art of Helping. 9th ed. Amherst (MA): Mass HRD Press. USA and Canada: Possibilities Publishing, Inc.; 2008.

16. Neimeyer RA, Maclnnes WD. Assessing paraprofessional competence with the Suicide Intervention Response Inventory. J Couns Psychol. 1981;28(2):176-179.

17. Kawashima D, Kawano K. The validity of the Japanese version of the suicide intervention response inventory. J Ment Health. 2013;59:67-74.

18. Skruibis P, Gailiene D, Hjelmeland H, et al. Attitudes towards suicide among regional politicians in Lithuania, Austria, Hungary, Norway and Sweden. Suicidol Online. 2010;1:79-87.

19. Brown MM, Range LM. Responding to suicidal calls: does trait anxiety hinder or help? Death Stud. 2005;29(3):207-216.

20. Neimeyer RA, Fortner B, Melby D. Personal and professional factors and suicide intervention skills. Suicide Life Threat Behav. 2001;31(1):71-82.

21. Shiang J. Does culture make a difference? Racial/ethnic patterns of completed suicide in San Francisco, CA 1987-1996 and clinical applications. Suicide Life Threat Behav. 1998;28(4):338-354.

22. Bertolote JM, Fleischmann A, De Leo D, et al. Suicide attempts, plans, and ideation in culturally diverse sites: the WHO SUPRE-MISS community survey. Psychol Med. 2005;35(10):1457-1465.

23. Scheerder G, Reynders A, Andriessen K, Van Audenhove C. Suicide intervention skills and related factors in community and health professionals. Suicide Life Threat Behav. 2010;40(2):115-124.

24. Cotton CR, Range LM. Reliability and validity of the suicide intervention response inventory. Death Stud. 1992;16(1):79-86.

25. Neimeyer RA, Hartley RE. Factorial structure of the suicide intervention response inventory. Suicide Life Threat Behav. 1986;16(4):434-447.

26. Slaikeu KA. Crisis Intervention: A Handbook for Practice and Research. 2nd ed. London: Pearson Education; 1990.

27. Palmieri G, Forghieri M, Ferrari S, et al. Suicide intervention skills in health professionals: a multidisciplinary comparison. Arch Suicide Res. 2008;12(3):232-237.
Neuropsychiatric Disease and Treatment

\section{Publish your work in this journal}

Neuropsychiatric Disease and Treatment is an international, peerreviewed journal of clinical therapeutics and pharmacology focusing on concise rapid reporting of clinical or pre-clinical studies on a range of neuropsychiatric and neurological disorders. This journal is indexed on PubMed Central, the 'PsycINFO' database and CAS,

\section{Dovepress}

and is the official journal of The International Neuropsychiatric Association (INA). The manuscript management system is completely online and includes a very quick and fair peer-review system, which is all easy to use. Visit http://www.dovepress.com/testimonials.php to read real quotes from published authors. 